\title{
A sobredotação na Região Autónoma da Madeira: Desenvolvimento de políticas e práticas educativas
}

\section{RESUMO}

A atenção à sobredotação e a alunos com altas capacidades, na Região Autónoma da Madeira (RAM), tem sido referenciada pelo seu pioneirismo no contexto português. Neste artigo descreve-se a evolução, desde os anos 90, dos mecanismos de atendimento das crianças e adolescentes com elevadas capacidades, e respetivo enquadramento legal. Os dados foram recolhidos a partir de entrevistas a alguns dos intervenientes neste processo e através da consulta de documentos disponíveis. Assim, foi possível organizar o percurso histórico da sobredotação na Madeira, apresentando um breve enquadramento da emergência do apoio à sobredotação e descrevendo três fases sequenciais do mesmo: (a) implementação de serviços de atendimento; (b) consolidação da prestação de serviços; e (c) serviços prestados na atualidade. De uma forma geral, apesar da evolução e modificação dos serviços, o investimento tem-se centrado no processo de identificação e de intervenção, na formação e na prática baseada em evidência, procurando fazer convergir as atuações com as orientações internacionais na área. Apontam-se algumas reflexões sobre as políticas públicas na área da sobredotação, tendo como premissa a escola inclusiva e uma melhoria de serviços que promovam a igualdade de oportunidades e a diferenciação das práticas educativas, em função das características e necessidades de cada aluno.

Palavras-chave: Sobredotação; Altas capacidades; Práticas educativas; Educação inclusiva.

\section{INTRODUÇÃO}

A questão da sobredotação e das altas capacidades tem carecido de consenso em relação à sua definição, assumindo o desempenho excecional um papel determinante na sua descrição e definição (Subotnik et al., 2011). Ao mesmo tempo, falta unanimidade relativamente aos processos a utilizar na identificação e no atendimento aos alunos com esse elevado potencial. A investigação demonstra a existência de tais alunos nas salas de aula e a necessidade de um acompanhamento específico de forma a desenvolverem plenamente as
Ana P. Antunes ${ }^{i}$

Universidade da

Madeira, Portugal

Leandro S. Almeida ${ }^{i i}$ Universidade do Minho, Portugal

Lúcia C. Mirandaiii Universidade da Madeira, Portugal

Joana O. Xavier ${ }^{i v}$ Secretaria Regional de Educação, Ciência e Tecnologia, Portugal

Conceição Ramos v Secretaria Regional de Educação, Ciência e Tecnologia, Portugal

Johanna M. Raffan vi National Association for Able Children in Education \& European Council for High Ability Inglaterra 
suas capacidades (Colangelo et al., 2004; Miranda \& Almeida, 2018), podendo alguns destes alunos apresentar, inclusive, significativas dificuldades na sua realização escolar (Tourón \& Pfeiffer, 2015). Neste quadro, a Declaração de Salamanca (UNESCO, 1994) preconiza uma educação inclusiva extensível a estes alunos, assumida como norteadora de políticas que salvaguardem a igualdade de oportunidades educativas tendo em atenção as necessidades e características dos alunos (Tourón \& Freeman, 2017). Para o efeito, as práticas conducentes a uma escola inclusiva requerem direções escolares comprometidas com a excelência académica (Torres, 2018; Torres \& Palhares, 2015), viabilizando agrupamento de alunos, aceleração curricular (e.g., fazer dois anos num ou saltando de ano, compactar conteúdos curriculares) ou atividades de enriquecimento centradas ou indo para além do currículo.

A existência de legislação que reconheça estes alunos e as suas necessidades educativas específicas revela-se fundamental (Torrano \& Sánchez, 2014; Tourón \& Freeman, 2017). Da mesma forma, é necessário alterar as práticas educativas dominantes em sala de aula, requerendo esta mudança formação dos professores e existência de serviços de apoio (Diez \& Fernández, 2018). De acordo com Subotnik e colaboradores (2011), a educação para os alunos sobredotados deve centrar-se na provisão de apoio ao seu desempenho, diminuindo o foco na eminência e valorizando a excelência. Para os mesmos autores, programas de intervenção junto destes alunos, dentro e fora da escola, são sobretudo necessários em comunidades de baixos recursos económicos e em contextos rurais.

Recentemente publicou-se em Portugal o Decreto-Lei no 54/2018, de 6 de julho, que explicita diretrizes para a promoção de uma educação inclusiva, assentes no desenho universal e na abordagem multinível, verificando-se, assim, o reconhecimento genérico de atenção para todos os alunos, mas não se encontram recomendações específicas para os alunos com altas capacidades. A propósito, deve referir-se que já no Decreto-Lei no $3 / 2008$, de 7 de janeiro, que regulamentava o regime de educação especial, agora revogado, também não se especificavam medidas educativas para os alunos com características de sobredotação. Este esquecimento nos enquadramentos legais mais globais não impediu alguns despachos fixando medidas excecionais para alguns destes alunos. Por exemplo ao nível da aceleração educativa, pode referir-se, mais recentemente, o Despacho Normativo no 1-F/2016, de 5 de abril, que permitia casos especiais de progressão.

\section{A SOBREDOTAÇÃO NA REGIÃO AUTÓNOMA DA MADEIRA (RAM)}

Falando da realidade portuguesa em matéria de atenção aos alunos com altas capacidades e características de sobredotação, uma referência particular é devida à RAM. No quadro da sua autonomia na área educativa, a RAM tem assumido um compromisso pioneiro no atendimento a estes alunos criando para o efeito diretivas, regulamentos e serviços (Antunes \& Almeida, 2008; Fleith et al., 2010). Este artigo pretende, então, descrever a implementação e consolidação desta política educativa na RAM. Para a sua concretização procedeu-se à recolha de informação junto de alguns dos intervenientes neste 
processo (consultores científicos e coordenadores de serviço) e à consulta de documentos disponíveis (legislação e artigos publicados). Para uma melhor sistematização da informação recolhida, e para responder aos objetivos fixados, este artigo toma uma perspetiva temporal considerando um breve enquadramento da emergência do apoio à sobredotação na RAM e três fases sequenciais do mesmo: (a) implementação de serviços de atendimento; (b) consolidação da prestação de serviços; e (c) serviços prestados na atualidade.

\subsection{ENQUADRAMENTO DA EMERGÊNCIA DO APOIO À SOBREDOTAÇÃO}

Prévio à apresentação do atendimento e enquadramento legal para os alunos talentosos ou com características de sobredotação na RAM, importa referir o trabalho pioneiro iniciado na década de 60 no âmbito da Educação Especial e Reabilitação. Por exemplo, é deste período o primeiro levantamento e despiste da deficiência auditiva na RAM, com o objetivo de seu atendimento educativo diferenciado, a cargo de uma equipa de profissionais conduzida pelo professor Eleutério de Aguiar e a professora Dina Gomes (Direção Regional de Educação, 2013). Assiste-se, assim, a um novo olhar e investimento na atenção à pessoa com deficiência, tendo-se criado, em 1968, à semelhança dos Centros de Educação Especial em Portugal continental, o Centro de Educação Especial da Madeira (CEEM), abarcando a deficiência auditiva, intelectual e visual. Assim, em 1978, decorrente da regionalização dos serviços, foi criado o Centro Regional de Educação Especial, que integrou, sob a sua tutela, as várias instituições de atendimento existentes, no âmbito de ação da Secretaria Regional dos Assuntos Sociais (SRAS) (Direção Regional de Educação, 2013). Neste contexto, relativamente ao enquadramento legal da Educação Especial na RAM, podemos destacar o Decreto Regional no 2/76, de 21 de outubro, que define o âmbito das competências da SRAS nos campos da saúde, segurança social e educação especial.

Na década de 80, o Decreto Regional no 13/81/M, de 23 de junho, define o âmbito de atuação da Direção Regional de Educação Especial (DREE) no seio da SRAS, especificando-se o seu Regulamento no Jornal Oficial Regional de 08 de junho de 1983, descrevendo-se atribuições e funções, nomeadamente: a "orientação e coordenação das actividades dos estabelecimentos oficiais que prosseguem actividades no âmbito da Educação Especial" (artigo 2); ou, ainda, "assegurar a integração social e familiar de crianças e adolescentes com deficiências auditivas, intelectuais, motoras e visuais e outras que exijam métodos especiais de acção" (artigo 3, alínea a). No âmbito de atuação ao nível das pessoas com deficiência foram também definidas linhas de ação visando o levantamento e despiste de situações de pessoas com deficiência e de medidas de apoio (Decreto Regional no 4/82/M, denominado "Prevenção, reabilitação e integração social dos deficientes"), pois:

De acordo com o Prof. Eleutério de Aguiar (1996), o levantamento e despiste da deficiência constitui a pedra de toque das políticas de prevenção da deficiência, incluindo todas as ações realizadas para reduzir a ocorrência da deficiência e o seu desenvolvimento em limitações funcionais. (Direção Regional de Educação, 2013) 
Neste sentido, na qualidade de Diretor da DREE, o professor Eleutério de Aguiar é reconhecido como o grande impulsionador da Educação Especial na RAM, um defensor da participação e da cidadania da pessoa com deficiência na sociedade madeirense e um lutador pela modificação das práticas educativas favoráveis à inclusão, incluindo aqui também os alunos com características de sobredotação.

\subsection{IMPLEMENTAÇÃO DE SERVIÇOS DE ATENDIMENTO}

\section{Programa Regional de Apoio aos Sobredotados (PRAS)}

A fase de implementação de serviços de apoio aos alunos sobredotados na RAM é assinalada com o início do PRAS, em 1995 (Direção Regional de Educação, 2013; Ramos et al., 2002). Para efeitos deste trabalho, considera-se como intervalo temporal para esta fase a data de início referida até, sensivelmente, o final da década de 90 (1995-2000). Nesta fase de implementação do PRAS desencadeia-se a criação de uma equipa de trabalho multidisciplinar (docentes do pré-escolar e de todos os ciclos do ensino básico, psicólogos, e profissionais da área social e de motricidade humana), sendo que, visando a mobilização das comunidades educativas, estes técnicos eram oriundos dos vários concelhos da RAM (Ramos et al., 2002). Assim, durante esta fase, não só foi desencadeada uma série de intervenções, como foi adotada legislação específica para estes alunos. Centrando-nos no enquadramento legal, no Decreto Regulamentar Regional no 13-A/97/M, de 15 de julho, também designado por Orgânica da DREER, merece referência a descrição das suas atribuições e competências:

a) Assegurar a educação e integração familiar e social das crianças, jovens e adultos com deficiências auditivas, ... ou portadores de sobredotação, que exijam métodos especiais de acção; d) Promover e participar em acções tendentes à prevenção, reabilitação e integração social das crianças, jovens e adultos deficientes ou sobredotados; e) Contribuir para a definição da política de educação, ensino especial e reabilitação, a favor das pessoas com deficiência ou sobredotação; j) Promover acções que fomentem a participação de crianças, jovens e adultos com deficiências ou sobredotação em actividades culturais, desportivas e recreativas; $m$ ) Sensibilizar a opinião pública para os problemas da educação, ensino especial e reabilitação, tendo em vista o reforço da solidariedade, da participação e da igualdade das pessoas com deficiência ou sobredotação na concretização do direito à formação e à integração social. (artigo 2)

Em termos das medidas práticas, e à semelhança do que aconteceu anteriormente em relação a outros grupos de alunos com necessidades especiais, a ação junto dos alunos sobredotados iniciou-se com um processo de despiste dos mesmos. Este levantamento, assumido como um dos principais objetivos do PRAS, destinava-se de forma explícita à definição de medidas para atender às necessidades de tais alunos e promover o seu desenvolvimento integral (Ramos et al., 2002). Assim, a par da criação da equipa de 
trabalho, houve também a preocupação de formação de professores e psicólogos, a adaptação e tradução de instrumentos de sinalização e intervenção, sendo este trabalho acompanhado por Johanna Raffan, que, além de consultoria científica, realizou ações de formação no âmbito do PRAS (e.g., sobre definição, avaliação e utilização de instrumentos, em 1995 e 1996).

Esta fase inicial pautou-se por um processo de identificação, onde se desencadearam mecanismos de sinalização e, posteriormente, de avaliação mais específica, sendo colocada ênfase "na avaliação das capacidades cognitivas e da criatividade. Esta avaliação foi precedida pela sinalização de crianças com níveis superiores de capacidade e/ou de desempenho pelos seus pais, educadores, professores, colegas ou eles próprios, através de checklists elaboradas para o efeito" (Ramos et al., 2002, p. 190).

\subsection{CONSOLIDAÇÃO DA PRESTAÇÃO DE SERVIÇOS}

Uma fase de consolidação destes serviços de apoio coincide, genericamente, com a primeira década do século XXI (2001-2011). Esta etapa caracteriza-se pela evolução da prestação de apoio aos sobredotados de três estruturas com diferentes designações e respetivas diretivas: (a) o Gabinete Coordenador de Apoio aos Sobredotados; (b) a Divisão Coordenadora de Apoio aos Sobredotados; e (c) a Divisão de Investigação em Educação Especial, Reabilitação e Sobredotação.

\section{Gabinete Coordenador de Apoio aos Sobredotados (GCAS)}

O Decreto Regulamentar Regional no 28/2001/M, de 20 de outubro, aprova a orgânica da Direcção Regional de Educação Especial e Reabilitação (DREER), definindo nas suas atribuições:

b) Colaborar no despiste, encaminhamento e acompanhamento de crianças e jovens sobredotados ou potencialmente sobredotados para os quais sejam aconselháveis estratégias próprias de intervenção, bem como participar em projectos experimentais ligados ao estudo da sobredotação. (artigo 2)

Neste enquadramento, são também definidas as atribuições do GCAS:

1- a) Assegurar a investigação na área da sobredotação; b) Coordenar, supervisionar e colaborar na avaliação de todos os programas e projectos experimentais na área da sobredotação; c) Colaborar na identificação, observação, orientação, encaminhamento e acompanhamento de crianças e jovens sobredotados ou potencialmente sobredotados; d) Coordenar os recursos humanos necessários à intervenção multidisciplinar em crianças e jovens para os quais se aconselhem estratégias próprias de intervenção psicológica, social ou cognitiva. 2 - 0 GCAS é coordenado por um funcionário do respectivo serviço a designar pelo director regional, sob proposta do director de serviços. (artigo 15) 


\section{Divisão Coordenadora de Apoio aos Sobredotados (DCAS)}

O Decreto Regulamentar Regional no 16/2005/M, de 19 de abril, aprova a orgânica da DREER e a sua missão:

a) Assegurar a educação e integração sócio-familiar de crianças, jovens e adultos portadores de deficiência e ou quaisquer outras necessidades educativas que exijam métodos especiais de intervenção; b) Colaborar no despiste, encaminhamento e acompanhamento de crianças e jovens sobredotados ou potencialmente sobredotados para os quais sejam aconselháveis estratégias próprias de intervenção, bem como participar em projectos experimentais ligados ao estudo da sobredotação. (artigo 2)

Além disso, define as atribuições da DCAS, que se apresentam com esta formulação:

1. a) Assegurar a investigação na área da sobredotação; 2 .

b) Coordenar, supervisionar e colaborar na avaliação de todos os programas e projectos experimentais na área da sobredotação; 3 . c) Colaborar na identificação, observação, orientação, encaminhamento e acompanhamento de crianças e jovens sobredotados ou potencialmente sobredotados; 4. d) Coordenar os recursos humanos necessários à intervenção multidisciplinar em crianças e jovens para os quais se aconselhem estratégias próprias de intervenção psicológica, social ou cognitiva. (artigo 19)

\section{Divisão de Investigação em Educação Especial, Reabilitação e Sobredotação (DIEERS)}

Na sequência da reestruturação do Governo da RAM, o Decreto Regulamentar Regional no 14/2008/M, de 30 de junho, aprova a nova orgânica da DREER, que nas suas atribuições continua o apoio aos sobredotados:

b) Colaborar no despiste, avaliação especializada, encaminhamento e acompanhamento de crianças e jovens com sobredotação ou potencialmente sobredotados para os quais sejam aconselháveis estratégias específicas de intervenção, bem como desencadear e participar em projectos experimentais ligados ao estudo da sobredotação; ... p) Desencadear a investigação científica através da implementação de projectos experimentais no âmbito da educação especial, reabilitação e sobredotação. (artigo 3)

Além disso, regulamenta (no artigo 9, ponto 7) a transição da Divisão Coordenadora de Apoio aos Sobredotados (DCAS) para a DIEERS (Divisão de Investigação em Educação Especial, Reabilitação e Sobredotação), sendo que, de acordo com o Despacho no 89/2008, de 11 de novembro, compete à DIEERS: 
a) Dinamizar projectos experimentais de investigação-acção, subjacentes ao estudo e à divulgação dos diferentes percursos evolutivos, boas práticas e perspectivas inovadoras em matéria de educação especial, reabilitação e sobredotação; b) Realizar e apoiar projectos de estudo e investigação científica na área de educação especial, reabilitação e sobredotação. (artigo 4)

Nesta fase de consolidação é importante referir a entrada em vigor do Decreto Legislativo Regional no 33/2009/M, de 31 de dezembro, que estabelece o regime jurídico da educação especial, transição para a vida adulta e reabilitação das pessoas com deficiência ou incapacidade na RAM (uma adequação regional do Decreto-Lei no 3/2008, de 7 de janeiro, que regulamentava o regime de educação especial em Portugal continental). Este documento legislativo apresenta uma definição de sobredotação (artigo 6, alínea j) como "a manifestação de capacidades acima da média, quando comparado com os pares da mesma faixa etária, experiência e origem social, assumindo níveis elevados de envolvimento na tarefa e níveis elevados de criatividade, aplicados a uma ou várias áreas de performance humana". Além disso, a sobredotação é também considerada como uma possibilidade no processo de referenciação (artigo 18: "1- A educação especial pressupõe a referenciação das crianças e jovens que eventualmente dela necessitem, a qual deve ocorrer o mais precocemente possível, detectando os factores de risco associados às limitações, incapacidades ou sobredotação"), nas possíveis medidas educativas, nomeadamente nas adequações curriculares individuais (artigo 30, ponto 2: "c). Na introdução de objectivos e conteúdos intermédios em função das competências terminais do ciclo ou de curso, das características de aprendizagem, de sobredotação e de dificuldades específicas dos alunos") e nas adequações ao processo de matrícula (artigo 31: "7- As crianças com características de sobredotação ou que manifestem precocidade no seu desenvolvimento global podem, em situações excepcionais, beneficiar da antecipação na matrícula no $1^{\circ}$ ano do $1^{\circ}$ ciclo do ensino básico").

Quanto à intervenção, encontra-se também uma referência explícita à mesma sob a designação de "apoio aos alunos sobredotados", onde se lê:

Compete à Direcção Regional de Educação Especial e Reabilitação desencadear mecanismos de despiste, avaliação e acompanhamento a crianças e jovens sobredotados, potencialmente sobredotados e ou talentosos através da investigação e aplicação de estratégias específicas de intervenção, sob a forma de medidas de antecipação e progressão, actividades de enriquecimento ou outro tipo de programa, de acordo com a legislação em vigor. (Decreto Legislativo Regional no 33/2009/M, artigo 40)

No que respeita à sobredotação, apesar das modificações operadas em termos de nomenclatura dos serviços, bem como das normativas legais, encontra-se um denominador comum em crescendo, ou seja, a preocupação com a identificação, o atendimento no seio de uma educação inclusiva e a realização de estudos de suporte às práticas. Assim, nesta fase de consolidação 
de práticas, a formação com peritos continuou a realizar-se (e.g., a formação "Ferramentas para pensar", por Marsyl Mettrau, em 2001), bem como os encontros de debate científico e profissional, onde a temática da sobredotação também era debatida (e.g., o I Encontro Regional de Educação especial na RAM - Almeida \& Pereira, 2003), ou onde era o tópico central do encontro (e.g., o Seminário “Sobredotação: Perspetivas, Percursos e Desafios”, em 2011).

A destacar, numa lógica de prática baseada em evidência, a importância do estabelecimento de parcerias e consultoria científica com algumas universidades portuguesas, em particular a Universidade do Minho (Teixeira, 2011). Assim, foi possível a implementação e avaliação de programas de enriquecimento desenvolvidos, quer no $1 .^{\circ}$ ciclo (essencialmente na área cognitiva, na Escola EB1/PE da Nazaré) quer no 2.ํㅜ ciclo de escolaridade (na linha cognitiva, mas também criatividade e dinâmica de grupo, na escola EB2,3 dos Louros, em horário extra-curricular) (Leitão et al., 2005), estudos de validação de provas pertinentes para o procedimento de avaliação de alunos com altas capacidades (Pocinho et al., 2007; Ramos et al., 2002; Sousa et al., 2002) e de conhecimento das perceções dos profissionais sobre a temática (Leitão et al., 2006). A realização destas atividades pressupôs o desenvolvimento de projetos diversificados, quer se tratasse da validação de instrumentos ou de intervenção direta com os alunos ou com os professores (Pinto \& Ramos, 2003). 0 estabelecimento de parcerias, o trabalho em rede, e em equipa, foram condições necessárias para a realização destas atividades, referindo-se ainda, por exemplo, a possibilidade de participação de alguns alunos no programa de verão realizado pela Associação Nacional para o Estudo e Intervenção na Sobredotação (ANEIS) em Portugal continental. A nível regional, uma atenção crescente foi dada também ao talento, além das capacidades cognitivas, e foram criadas oportunidades de crecimento em algumas áreas como, por exemplo, a realização de jogos de estratégias (damas e xadrez) e a expressão plástica, orientadas por peritos das respetivas áreas, ou o projeto de Mitologia Clássica e Escrita Criativa, na Universidade da Madeira (Direção Regional de Educação, 2013). Mais recentemente, no ano letivo 2010/2011, de assinalar a parceria da DIEERS com entidades que permitiram realizar atividades de enriquecimento no âmbito das artes e da cultura com a colaboração de uma escola (APEL) e de um museu (Museu Henrique e Francisco Franco), e no âmbito do desenvolvimento motor com a colaboração da Universidade da Madeira e do Clube de Amigos do Basquete (Teixeira, 2011).

\subsection{SERVIÇOS PRESTADOS NA ATUALIDADE}

A fase atual, para efeitos deste trabalho, corresponde aos últimos anos (desde 2012) e caracteriza-se pela continuidade de evolução das estruturas de prestação de apoio aos sobredotados e respetivas designações, neste caso, em três momentos: (a) o Núcleo de Apoio à Sobredotação; (b) o Gabinete de Apoio à Sobredotação; e (c) o Gabinete de Apoio às Altas Capacidades.

\section{Núcleo de Apoio à Sobredotação (NAS)}

Esta etapa, que decorre de 2012 a 2016, coincide com a vigência do Decreto Legislativo Regional no 33/2009/M, de 31 de dezembro, com referência aos alunos sobredotados como alunos com necessidades educativas especiais 
(NEE). Entretanto, o Decreto Regulamentar Regional no 14/2008/M, de 30 de junho, foi revogado pelo Decreto Regulamentar Regional no 8/2012/M, de 18 de junho, que aprova a orgânica da Direção Regional de Educação (DRE) e, nas suas atribuições (artigo 3), estabelece o apoio a alunos com NEE, especificando-se as suas unidades orgânicas na Portaria no 83/2012, de 22 de junho, e o apoio aos alunos sobredotados na dependência da Direção de Serviços de Apoios Técnicos Especializados (artigo 5). Posteriormente, no Despacho no 6/2012, de 25 de junho, que retifica a criação das unidades orgânicas nucleares da DRE e define que, na dependência da Direção de Serviços de Apoios Técnicos e Especializados (DSATE), funcionará a Divisão de Apoio Psicológico e Orientação Escolar e Vocacional (artigo 1, ponto 5, alínea b), a qual terá na sua dependência o NAS (artigo 12, ponto 2).

O NAS constituiu-se, então, com dois objetivos centrais, um relacionado com o processo de identificação e intervenção e outro com a produção de estudos científicos (Pinto et al., 2015). Dessa forma, as linhas de ação desenvolveram-se em três eixos que "se articulam entre si: (1) Processo de sinalização e avaliação; (2) Processo de intervenção; (3) Elaboração de artigos e materiais de carácter científico e/ou técnico, cuja temática central é a sobredotação e/ou talento" (Pinto et al., 2015, p. 25). Mais concretamente, o NAS desenvolveu ações que se caracterizam pela formação no âmbito da sobredotação, participação em reuniões de discussão de casos, realização de conferências, colaboração em estudos sobre a sobredotação, construção de materiais, contacto com a comunidade no sentido de elencar oportunidades de desenvolvimento de capacidades em áreas específicas, e, finalmente, atividades de enriquecimento mais prolongadas no tempo (e.g., o programa "Enriquecer com xadrez") e outras mais pontuais e em áreas distintas (e.g., Hapkido, uma arte marcial, e Yoga) (Pinto et al., 2015).

\section{Gabinete de Apoio à Sobredotação (GAS)}

Esta penúltima etapa, de 2016 até 2020 , pode ser cunhada pela publicação do Despacho no 110/2016, de 21 de março, que aprova a estrutura flexível da DRE e onde são estabelecidas as respetivas competências. No seu artigo 10, referente às atribuições da Divisão de Acompanhamento Educativo Especializado, na alínea e) é referido: "prestar apoio aos estabelecimentos de educação e ensino, famílias e unidades de saúde pública e de segurança social no despiste, observação, avaliação, encaminhamento ou atendimento de crianças e jovens com incapacidades, deficiência, outras necessidades educativas especiais e sobredotação". No artigo 16, relativo à Divisão de Apoios Técnicos Especializados, considera-se, no ponto 3, que "na dependência da Divisão de Apoios Técnicos Especializados funciona o Gabinete de Apoio à Sobredotação (GAS)", sendo que, no artigo 17, lhe são atribuídas as seguintes competências:

a) Colaborar na avaliação, diagnóstico, encaminhamento e acompanhamento de crianças e jovens sobredotados, talentosos e ou potencialmente sobredotados; b) Prestar consultadoria aos profissionais que intervêm na área da sobredotação e talentos; c) Cooperar no desenvolvimento, implementação e avaliação de projetos e programas 
na área da sobredotação e talentos; d) Colaborar em projetos de investigação na área da sobredotação e talentos; e) Elaborar propostas e emitir pareceres no âmbito da sobredotação e talentos. (Despacho no 110/2016, artigo 17)

Embora o Despacho no 152/2017, de 23 de março, proceda à alteração do Despacho no 110/2016, de 21 de março, que aprovou a estrutura flexível da DRE, e estabeleceu as respetivas competências, no que se refere ao apoio aos alunos sobredotados estas são mantidas inalteradas. Assim sendo, a atuação do GAS tem-se caracterizado por procurar responder às competências que lhe estão atribuídas, destacando-se o que designa por Programa Saber e Ser Mais (Saber e Ser + ). Importa ainda a referência a atividades de enriquecimento em áreas específicas (o projeto Astronomia e Matemática, em parceira com a Universidade da Madeira) e áreas transversais (oficinas de yoga, teatro, e de inteligência emocional), e, ainda, a formação para pais e técnicos (e.g., tertúlia sobre a sobredotação realizada por África Borges) (Gabinete de Apoio à Sobredotação, 2018).

\section{Gabinete de Apoio às Altas Capacidades (GAAC)}

Esta última etapa, iniciada recentemente (2020), é marcada pela publicação da Portaria no 113/2020, de 6 de abril de 2020, referente a uma nova estrutura nuclear da Direção Regional de Educação, definindo-se as atribuições e competências das suas unidades orgânicas, e decorrente da reconfiguração organizativa publicada no Decreto Regulamentar Regional no 2/2020/M, de 9 de janeiro, que aprova a orgânica da Secretaria Regional de Educação, Ciência e Tecnologia. Assim, a estrutura de apoio mais direta aos alunos sobredotados está suportada pelo Despacho no $141 / 2020$, de 9 de abril, e também sofre uma nova designação, Gabinete de Apoio às Altas Capacidades (GAAC), sendo que continua a funcionr na dependência da Divisão de Apoios Técnicos Especializados, tendo atribuições similares às do GAS:

a) Colaborar com os estabelecimentos de educação e ensino e outros serviços, no processo de avaliação e intervenção de crianças e alunos com altas capacidades; b) Colaborar na planificação e implementação de medidas de suporte à aprendizagem e à inclusão; c) Prestar consultadoria aos profissionais que intervêm nesta área; d) Cooperar no desenvolvimento, implementação e avaliação de programas e projetos na área das altas capacidades; e) Elaborar propostas e emitir pareceres no âmbito específico das suas atribuições. (Despacho no 141/2020, artigo 19)

\section{CONSIDERAÇÕES FINAIS}

Este artigo traçou uma panorâmica do desenvolvimento das políticas e práticas educativas na Região Autónoma da Madeira (RAM) no atendimento educativo diferenciado aos alunos talentosos e com características de sobredotação. 0 investimento e a alocação de recursos, associado à criação de 
legislação e diretrizes próprias, acentuam o pioneirismo da RAM no contexto português. Sobretudo, importa destacar a convergência deliberadamente procurada entre legislação, criação de serviços, alocação de técnicos (equipas multidisciplinares) e a formação especializada dos profissionais envolvidos. Nesta convergência está a razão do sucesso na implementação e consolidação do atendimento destes alunos, no quadro de uma educação e uma escola inclusivas, movimento este que na RAM se iniciou antes da Declaração de Salamanca, onde estes princípios foram assumidos pela UNESCO (1994).

Importa continuar a apoiar ações que promovam o desenvolvimento destes alunos, a investir em ações de formação, pois nem sempre acontece os professores possuírem conhecimentos sobre a legislação existente e saberem como aplicá-la, ou sobre a identificação e a intervenção a desencadear (Rodrigues \& Antunes, 2012; Torrano \& Sánchez, 2014). Acredita-se que talvez assim o número de alunos identificados com caracteríscticas de sobredotação e altas capacidades comece a aproximar-se do que seria efetivamente esperado, por exemplo, seguindo o critério estatístico da ocorrência de certos fenómenos psicológicos na população (Torrano \& Sánchez, 2014).

Uma escola inclusiva de qualidade implica não só a criação de serviços especializados de apoio, mas também lideranças pedagógicas favoráveis à excelência, nomeadamente a excelência académica (Torres, 2018; Torres \& Palhares, 2015). Na RAM, este incentivo à excelência e a atenção à sobredotação tem decorrido da adequada convergência entre legislação e criação de serviços específicos. Por outro lado, e progressivamente, este movimento apoiou-se na realização de estudos tendo em vista a adaptação de instrumentos de avaliação das características de tais alunos e a avaliação da eficácia das medidas educativas implementadas (Leitão et al., 2005, 2006; Teixeira, 2011). Com todas estas condições criadas, espera-se que o pioneirismo da criação do PRAS, na década de 90, prossiga no seu desenvolvimento e atualização, tendo em vista as formas de identificação e de atendimento dos alunos com características de sobredotação e altas capacidades.

\section{REFERÊNCIAS}

Almeida, L. S., \& Pereira, M. (2003). Os alunos sobredotados numa escola e sociedade inclusivas: Alguns desafios e respostas possíveis por parte do sistema educativo. Revista Diversidades, 2, 24-30.

Antunes, A., \& Almeida, L. (2008). 0 atendimento educativo dos sobredotados: Ritmos diferentes nos Estados Unidos, na Europa e em Portugal. Revista Diversidades, 19, 4-8.

Colangelo, N., Assouline, S. G., \& Gross, M. U. M. (2004). A nation deceived: How schools hold back America's brightest students (vol. I). lowa City: University of lowa, Belin-Blank Center. Consultado em 05/09/2018 em http://www. accelerationinstitute.org/nation_deceived/ND_v1.pdf

Diez, L. P., \& Fernández, C. J. (2018). Influencia de la organización escolar en la educación de los alumnos de altas capacidades. Enseñanza \& Teaching, 36(1), 151-178. https://doi.org/10.14201/et2018361151178

Direção Regional de Educação. (2013). 0 percurso da educação especial 
na Região Autónoma da Madeira. Revista Diversidades, 42, 4-49.

Fleith, D. S., Almeida, L. S., Alencar, E. M. S., \& Miranda, L. (2010). Educação do aluno sobredotado no Brasil e em Portugal: Uma análise comparativa. Revista Lusófona de Educação, 16, 75-88.

Gabinete de Apoio à Sobredotação. (2018). Programa Saber e Ser + [Relatório de atividades]. Documento não publicado. Funchal, Direção Regional de Educação.

Torrano, D., \& Sánchez, M. (2014). El estudio de la alta capacidad intelectual en España: Análisis de la situación actual. Revista de Educación, 364, 251-272. https://doi.org/10.4438/1988-592X-RE-2014-364-261

Leitão, A. I., Ramos, C., Jardim, J., Correia, V., \& Almeida, L. S. (2005). Enriquecimento cognitivo com alunos portadores de altas habilidades: Experiência no $1 .^{\circ}$ e $2 .^{\circ}$ ciclos do ensino básico. Sobredotação, 6, 127-137.

Leitão, A. I., Ramos, C., Jardim, J., Correia, V., \& Almeida, L. S. (2006). Percepção dos professores e psicólogos na área da sobredotação. Sobredotação, 7, 103-117.

Miranda, L. C., \& Almeida, L. S. (2018). Sobredotação em Portugal: Legislação, investigação e intervenção. In L. S. Almeida \& A. Rocha (Coords.), Sobredotação: Uma responsabilidade coletiva! (pp. 265-287). CERPSI.

Pinto, N., \& Ramos, C. (2003). A experiência na avaliação e atendimento do aluno sobredotado na RAM. Revista Diversidades, 2, 31-32.

Pinto, N., Xavier, J., Henriques, M., \& Domingos, R. (2015). Um breve périplo pelo apaixonante mundo da sobredotação. Revista Diversidades, 46, 23-31.

Pocinho, M., Almeida, L., Ramos, M. C., Correia, V., Rodrigues, P., \& Correia, A. (2007). Atribuições causais para o bom e fraco desempenho escolar: Estudo com alunos do 3. ${ }^{\circ}$ ciclo do ensino básico. Revista Psicologia, Educação e Cultura, 11(2), 343-355.

Ramos, C., Pinto, I., Correia, L. V., \& Santos, L. (2002). Aferição de instrumentos de avaliação cognitiva junto da população estudantil da Região Autónoma da Madeira. Sobredotação, 3(2), 189-205.

Rodrigues, C., \& Antunes, A. P. (2012). Escola inclusiva e sobredotação: Estudo exploratório sobre as pecepções dos professores. In L. S. Almeida, B. D. Silva, \& A. Franco (Orgs.), Actas do II Seminário Internacional "Contributos da Psicologia em Contextos Educativos" (pp. 637-647). CIEd-Universidade do Minho.

Sousa, A., Ramos, C., Santos, L., Correia, L. V., Almeida, L. S., \& Oliveira, E. P. (2002). Bateria de provas de raciocínio (BPR5-6): Contributos para a sua validação e aferição. Sobredotação, 3(2), 231-244.

Subotnik, R. F., Olszewski-Kubilius, P., \& Worrell, F. C. (2011). Rethinking giftedness and gifted education: A proposed direction forward based on psychological science. Psychological Science in the Public Interest, 12(1), 3-54. http:// doi.org/10.1177/1529100611418056

Teixeira, M. (2011). A intervenção da DREER na sobredotação: Presente e futuro. Revista Diversidades, 34, 19-20.

Torres, L. L. (2018). Culturas de escola e excelência: Entre a integração de todos e a distinção dos melhores. Revista de Sociología de la Educación (RASE), 11(1), 167-185. https://doi.org/10.7203/RASE.10.1.9135 
Torres, L. L., \& Palhares, J. A. (2015). Cultura, liderança e resultados escolares: Uma abordagem a partir das representações dos alunos do ensino secundário. Revista Lusófona de Educação, 30, 99-121. Consultado em 18/09/2018 em http://revistas.ulusofona.pt/index.php/rleducacao/article/view/5131

Tourón, J., \& Freeman, J. (2017). Gifted education in Europe: Implications for policymakers and educators. In S. I. Pfeiffer (Ed.), APA Handbook on giftedness and talent (pp. 54-70). Washington: American Psychological Association. Consultado em 18/09/2018 em https://www.joanfreeman.com/pdf/Gifted-Education-in-Europe.pdf

Tourón, J., \& Pfeiffer, S. (2015). Alta capacidad y desarrollo del talento: Aspectos críticos. Revista de Educación, 368, 9-11.

UNESCO. (1994). Declaração de Salamanca sobre princípios, política e práticas na área das necessidades educativas especiais. Consultado em 18/09/2018 em https://unesdoc.unesco.org/ark:/48223/pf0000110753

\section{LEGISLAÇÃO}

Decreto Legislativo Regional n. ${ }^{\circ}$ 33/2009/M, de 31 de dezembro, Região Autónoma da Madeira - Assembleia Legislativa, Diário da República n. ${ }^{\circ}$ 252/2009, Série I, pp. 8330-8859.

Decreto Regional n. ${ }^{\circ}$ 13/81/M, de 23 de junho, Região Autónoma da Madeira - Assembleia Regional, Diário da República n. ${ }^{0}$ 141/1981, Série I, pp. 1451-1458.

Decreto Regional n. ${ }^{\circ}$ 4/82/M, Região Autónoma da Madeira - Assembleia Regional, Diário da República n. ${ }^{\circ}$ 76/1982, Série I, pp. 752-754.

Decreto Regulamentar Regional n. ${ }^{\circ} 13-A / 97 / M$, de 15 de julho, Região Autónoma da Madeira - Presidência do Governo, Diário da República n. ${ }^{\circ}$ 161/1997, $2^{\circ}$ Suplemento, Série I-B, 3504-(6)-3504-(18).

Decreto Regulamentar Regional n. ${ }^{\circ}$ 14/2008/M, de 30 de junho, Região Autónoma da Madeira - Presidência do Governo, Diário da República n. ${ }^{\circ}$ 124/2008, Série I, pp. 4080-4084.

Decreto Regulamentar Regional n. ${ }^{\circ}$ 16/2005/M, de 19 de abril, Região Autónoma da Madeira - Presidência do Governo, Diário da República n. ${ }^{\circ}$ 76/2005, Série I-B, pp. 3093-3106.

Decreto Regulamentar Regional n.o 2/2020/M, de 9 de janeiro, Região Autónoma da Madeira - Presidência do Governo, Diário da República n. ${ }^{\circ}$ 6/2020, Série I, pp. 12-22.

Decreto Regulamentar Regional n. ${ }^{\circ}$ 28/2001/M, de 20 de outubro, Região Autónoma da Madeira - Presidência do Governo, Diário da República n. ${ }^{\circ}$ 244/2001, Série I-B, pp. 6680 - 6695.

Decreto Regulamentar Regional n. ${ }^{\circ}$ 8/2012/M, de 18 de junho, Região Autónoma da Madeira - Presidência do Governo, Diário da República n. ${ }^{\circ}$ 116/2012, Série I, pp. 3019-3021.

Decreto-Lei n. ${ }^{0} 3 / 2008$, de 7 de janeiro, Ministério da Educação, Diário da República n. ${ }^{\circ}$ 4/2008, Série I, pp. 154-164.

Decreto-Lei n. ${ }^{0}$ 54/2018, de 6 de julho, Presidência do Conselho de Ministros, Diário da República n. ${ }^{\circ}$ 129/2018, Série I, pp. 2918-2928.

Despacho n. ${ }^{0}$ 100/2013, de 12 de junho, Secretaria Regional de Educação e Recursos Humanos, Jornal Oficial da Região Autónoma da Madeira, Série II, n. ${ }^{\circ} 110$, pp. 1-12. 
Despacho n. ${ }^{\circ}$ 110/2016, de 21 de março, Secretaria Regional de Educação, Jornal Oficial da Região Autónoma da Madeira, Série II, n. ${ }^{\circ}$ 52, pp. 5-12.

Despacho n.o 141/2020, de 9 de abril, Secretaria Regional de Educação, Ciência e Tecnologia, Jornal Oficial da Região Autónoma da Madeira, Série II, n. ${ }^{\circ}$ 70, pp. 2-9.

Despacho n. ${ }^{\circ}$ 152/2017, de 23 de março, Secretaria Regional de Educação, Jornal Oficial da Região Autónoma da Madeira, Série II, n. ${ }^{\circ}$ 53, pp. 1-10.

Despacho Normativo n. ${ }^{0}$ 1-F/2016, de 5 de abril, Educação - Gabinete do Secretário de Estado da Educação, Diário da República n. ${ }^{\circ}$ 66/2016, 1. ${ }^{\circ}$ Suplemento, Série II, pp. 11440-(3) - 11440-(10).

Portaria n.o 113/2020, de 6 de abril de 2020, Vice-Presidência do Governo Regional e dos Assuntos Parlamentares e Secretaria Regional de Educação, Ciência e Tecnologia, Jornal Oficial da Região Autónoma da Madeira, Série I, n. ${ }^{\circ}$ 80, pp. 9-13.

Portaria n. ${ }^{\circ}$ 83/2012, de 22 de junho, Vice-Presidência do Governo Regional e Secretarias Regionais do Plano e Finanças e da Educação e Recursos Humanos, Jornal Oficial da Região Autónoma da Madeira, Série I, n. ${ }^{\circ}$ 80, pp. 5-9.

Regulamento da Direção Regional de Educação Especial, de 08 de junho de 1983, Secretaria Regional dos Assuntos Sociais, Jornal Oficial da Região Autónoma da Madeira, Série I, n. ${ }^{\circ}$ 17, pp. 1-10.

Informação dos autores:

i Universidade da Madeira, Departamento de Psicologia; Universidade do Minho, Centro de Investigação em Estudos da Criança, Portugal. https://orcid.org/0000-0002-3336-7867 ii Universidade do Minho, Centro de Investigação em Educação, Portugal. https://orcid.org/0000-0002-0651-7014

iii Universidade da Madeira, Departamento de Psicologia, Portugal. https://orcid.org/0000-0002-0652-0811

iv Secretaria Regional de Educação, Ciência e Tecnologia, Direção Regional de Educação, Portugal.

https://orcid.org/0000-0002-5529-7281

v Secretaria Regional de Educação, Ciência e Tecnologia, Direção Regional de Educação, Portugal.

https://orcid.org/0000-0002-7326-4969

vi National Association for Able Children in Education; European Council for High Ability, Inglaterra. https://orcid.org/0000-0003-1017-4410

Toda a correspondência relativa a este artigo deve ser enviada para:

Ana Pereira Antunes

Faculdade de Artes e Humanidades,

Campus Universitário da Penteada

9020-105 Funchal, Portugal

aantunes@uma.pt

Recebido em 2 de outubro de 2019

Aceite para publicação em 21 de abril de 2020 


\title{
Giftedness in the Autonomous Region of Madeira: Development of policies and educational practices
}

\begin{abstract}
Attention to giftedness and high ability students, in the Autonomous Region of Madeira (RAM), has been acknowledged for being pioneer in Portugal. The main purpose of this paper is to outline the evolution of practices for high abilities students, and their legal framework, since the 90s, in RAM. Data were collected from interviews with some of the actors in this process and through analysis of available documents. Thus, it was possible to organise the historical path of giftedness in Madeira. So, it is presented a brief framework of the emergence of giftedness educational support and three sequential phases are also described: (a) implementation of support services; (b) consolidation of the provision of services; and (c) current services provided. In general, despite the evolution and modification of the organisation of the services, the investment has been centered on the identification and intervention process, on training and on evidence-based practice, seeking convergence of intervention with international guidelines. Some reflections on public policies about giftedness are pointed out, based on the premise of an inclusive school and a possible improvement of practices that might facilitate equal opportunities and differentiation of educational practices, according to the characteristics and needs of each student.
\end{abstract}

Keywords: Giftedness; High ability students;

Educational practices; Inclusive education 


\section{La superdotación en la Región Autónoma de Madeira: Desarrollo de políticas y prácticas educativas}

\section{RESUMEN}

La atención a los estudiantes superdotados y con altas capacidades en la Región Autónoma de Madeira (RAM) se ha mencionado como pionera en el contexto portugués. En este estudio se pretende trazar la evolución de los mecanismos de atención de los niños y adolescentes con altas capacidades en la RAM, con su respectivo marco legal, de lo que viene sucediendo desde los años 90. Los datos fueron recogidos a partir de entrevistas a algunos de los participantes en este proceso y a través de la consulta de documentos disponibles. Así, fue posible organizar el recorrido histórico de la superdotación en Madeira, presentando un breve encuadre del surgimiento del apoyo a la sobredotación y describiendo tres fases secuenciales del mismo: (a) implementación de servicios de atención; (b) consolidación de la prestación de servicios; y (c) servicios prestados en la actualidad. En general, a pesar de la evolución y la modificación de los servicios, la inversión se ha centrado en el proceso de identificación y de intervención, en la formación y en la práctica basada en evidencia, buscando hacer converger las actuaciones con las orientaciones internacionales en el área. Se apuntan algunas reflexiones sobre las políticas públicas en el área de la superdotación, teniendo como premisa la escuela inclusiva y una posible mejora de servicios que pueda facilitar la igualdad de oportunidades y la diferenciación de las prácticas educativas en función de las características y necesidades de cada alumno.

Palabras clave: Superdotación; Altas capacidades; Prácticas educativas; Educación inclusiva 